\title{
Comparative Study of Intralesional Dexamethasone Plus Hyaluronidase \& Oral Colchicine in Patients with Oral Submucous Fibrosis
}

\author{
Neupane $\mathrm{GP}^{1}$, Rai $\mathrm{M}^{2}$, Rathor $\mathrm{RS}^{3}$, Bhargava $\mathrm{VK}^{4}$, Mahat $\mathrm{AK}^{5}$, Dhami $\mathrm{DB}^{6}$
}

\begin{abstract}
Introduction: Oral Submucous Fibrosis (OSMF) is a precancerous condition of the oral mucosa. It is characterized by excessive production of collagen leading to inelasticity of the oral mucosa and atrophic changes of the epithelium. Aim and objective: To evaluate the efficacy of oral Colchicine in comparison to intralesional injections of Dexamethasone plus Hyaluronidase in the management of OSMF patients. Materials and Methods: Fourty patients with OSMF were randomly divided equally into two groups. 20 patients in Dexamethasone group received biweekly intralesional injections of Dexamethasone (4mg/ml) plus Hyaluronidase $1500 \mathrm{IU}$ in buccal mucosa for a period of 12 weeks. Other 20 patients in Colchicine group received oral Colchicine 0.5 mg tablets twice daily for 12 weeks. Parameters taken in the study were burning sensation, and mouth opening. Descriptive statistics, paired t test and unpaired t test were used for statistical analysis. Results and Conclusions: The pre- and post-treatment differences were found to be statistically significant for both the groups $(p<0.001)$ and for both the treatment outcomes. When the average difference of the treatment outcomes was compared between the two study groups, statistically highly significant difference was noted $(p<0.001)$ only in mouth opening but not in burning sensation.These encouraging results should prompt further clinical trials with Colchicine on a larger sample size to broaden the therapeutic usefulness of the drug in the management of OSMF.
\end{abstract}

Key words: Anti-fibrotic, mouth opening, oral submucous fibrosis (OSMF)

\section{INTRODUCTION}

Oral Submucous Fibrosis (OSMF) is a debilitating but preventable oral disease ${ }^{1}$. A condition similar to OSMF was described as early as 600 BC by Sushruta, who named it "Vidari" which presented as progressive narrowing of the mouth, depigmentation of the oral mucosa and pain during eating. The first documentation of this disease during recent times came from Schwartz, who described a similar entity and designated the term "Atropical diopathica Mucosae Oris"' to this condition. Finally Joshi described this condition as "Submucous fibrosis"2.

Oral submucous fibrosis is a chronic insidious disease and a well recognized potentially malignant condition of the oral cavity characterized by inflammation and a progressive fibrosis of the lamina propria and deeper connective tissues. Although

\footnotetext{
1. Dr. Ganesh Prasad Neupane

2. Dr. Maya Rai

3. Prof. R. S. Rathore

4. Prof. V. K. Bhargava

5. Dr. A. K. Mahat

6. Dr. D. B. Dhami
}

\section{Address for correspondence} Ganesh Prasad Neupane Department of Pharmacology Nepalgunj Medical College, Chisapani, Banke, Nepal

E-mail: ganeshpn2003@yahoo.com occasionally preceded by vesicle formation, it is always associated with juxtaepithelial inflammatory reaction followed by a fibroelastic change of lamina propria with epithelial atrophy leading to stiffness of oral mucosa, causing trismus and inability to eat ${ }^{3}$.

The condition is seen predominantly in residents of Asia with more prevalence in India .Sporadic cases of OSMF have also been observed in Nepal, China, Thiland and South Vietnam ${ }^{4}$. OSMF has a multifactorial etiology. Several factors such as chilli consumption, nutritional deficiency states, areca nut chewing, genetic susceptibility, autoimmunity \& collagen disorders have been suggested to be involved in the pathogenesis of the condition $^{5}$. The main etiological agent causing the disease is confirmed as arecoline in arecanut ${ }^{6}$.

It is considered as a disorder of collagen metabolism and is characterized by increased production and decreased degradation of collagen fibers ${ }^{7}$. This leads to inelasticity of the oral mucosa and atrophic changes of the epithelium ${ }^{8}$. Thick inelastic rope like fibrous bands appear vertically in the buccal mucosa, along the contours of the faucial pillars and around the entire circle of lips thus leading to difficulty in mouth opening and narrowing of the rima oris ${ }^{9}$. The fibrosis also leads to difficulty in mastication, speech and swallowing, pain in the throat and the ears, burning sensation on taking spicy food, excessive salivation, defective gustatory sensation and progressive restriction of mouth opening and the protrusion of the tongue ${ }^{8}$ and a relative loss of auditory acuity due to stenosis of the opening of the eustachian tube. The most outstanding 
feature and the most reliable sign of oral submucous fibrosis is the presence of palpable bands in the oral mucosa, especially in the buccal mucosa. The disease, however, has other characteristic signs, such as diffuse blanching of the mucosa, occurrence of hyperpigmented areas adjacent to zones with loss of pigment, loss of tongue papillae, and a leathery consistency of the mucosa. A more serious complication of this disease is the risk of the development of oral squamous cell carcinoma (SCC), estimated to be 7.6 percent of cases over a 10 year period ${ }^{10}$.

Various treatment modalities have been tried to treat patients suffering from this disease. Medical interventions include dietary supplementation with vitamins, antioxidants, corticosteroid therapy, proteolytic agents such as hyalronidase and placental extracts and anticytokines ${ }^{11}$. Severe trismus and refractory cases are treated by surgical excision of fibrous bands ${ }^{3}$.

The main goal of the treatment of OSMF is to reduce trismus and burning sensation. One of the important therapeutic modalities is intralesional injection therapy. The most commonly used intralesional agents are placental extract, corticosteroids and hyaluronidase. The mechanism of action and therapeutic efficacy vary from one drug to another and their combinations used ${ }^{12}$.

Steroids have anti-inflammatory action which helps to provide symptomatic relief. It also has antifibrotic activity and prevents fibrosis by decreasing fibroblastic proliferation and deposition of collagen ${ }^{13}$. Hyaluronidase causes breakage and dissolution of fibrous bands thus providing relief from the condition. It acts by breaking down hyaluronic acid ${ }^{14}$.

The pharmacodynamics of Colchicine as an anti-fibrotic agent is well-established by various in vitro and in vivo studies warranting its use in the treatment of various diseases associated with fibrosis. Till now it is used specifically for acute gout $^{15,16,17}$.

In the course of disease treatment, convenience of drug administration is one of the factor for successful management of disease. As oral administration of drug is more convenient compared to intralesional drug administration, it would be ideal if a oral substitute to intralesional drug delivery is available in the management of OSMF.

Hence, anti-fibrotic along with anti-inflammatory properties of Colchicine that is surprisingly well tolerated, easily available, and cost effective, prompted us to embark on this study. This study is intended to compare the efficacy of oral Colchicine 0.5 $\mathrm{mg}$ Tablets twice daily with intralesional injections of Dexamethasone $(4 \mathrm{mg} / \mathrm{ml})+$ Hyaluronidase $1500 \mathrm{IU}$ bi- weekly in OSMF patients for 12 weeks period of active treatment. MATERIALS AND METHODS
This study was conducted in Nepalgunj Medical College Teaching Hospital, Nepal, Between November 2015 to October 2016 in Department of Dental Surgery and Pharmacology. Screening of Patients was done in various Dental clinic situated in mid western region of Nepal, and they were referred to Dental Department of Nepalgunj Medical College Teaching Hospital. The patients for the study were selected from those who visited Department. Prior to conducting the study, the subjects were explained the need for the study and a written consent was taken from them. Patients who were not taking any medications for OSMF previously were only included in the study.

Patients with known systemic diseases such as bleeding and clotting disorders, cardiac disorders, diabetes mellitus, renal or hepatic disorders, collagen diseases like scleroderma, thromboembolic disorders were excluded from the study. Also Patients not willing to participate in study or not ready to quit the use of quid were excluded from study. Patients having clinical or histological evidence of malignant change, extension of the disease either onto the pharynx or floor of mouth were also excluded. Patients having history of recent myocardial infarction, uncontrolled hypertension, diabetes, peptic ulcer, tuberculosis, and cirrhotic liver disease were all excluded as steroids can potentially worsen the aforementioned conditions.

A detailed case history of the patient with emphasis on their habits (chewing betel nut, pan parag, guthkha etc.) was taken. Clinical examination conducted and was recorded on a standard proforma.

VAS scale was used to record the severity of burning sensation in the patients, with the severity of symptoms extending from a numerical 0 (no pain or discomfort) to 10 (severe most pain /discomfort). Patients' maximum mouth opening was measured using vernier calipers. Mouth opening was measured by measuring the distance between the centre of incisal edges of maxillary central incisors and mandibular central incisor at maximum opened mouth position ${ }^{18}$.

A clinical diagnosis of OSMF was made and the patients were graded clinically according to the classification of Ranganathan $\mathrm{K}$ et al. ${ }^{27}$ The subjects were counselled to quit the habit during the study period. Fourty patients in the age group of (19-48 years), thus diagnosed as having OSMF, were included in the study and were divided randomly into two groups for the purpose of treatment.

Fourty patients with OSMF were randomly divided equally into two groups.Twenty patients were in Oral Colchicine group and 20 patients in Injection Dexamethasone + Hyaluronidase group. Colchicine Group received oral Colchicine $0.5 \mathrm{mg}$ tablets twice daily for a period of 12 weeks. Dexamethasone Group received biweekly intralesional injections of Dexamethasone 


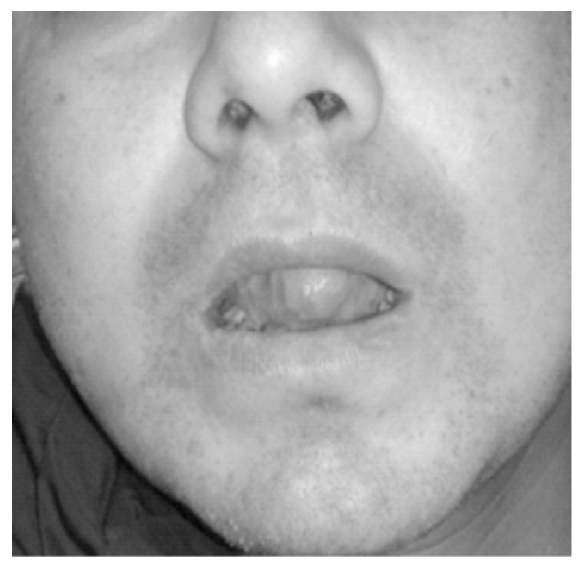

Figure 1: Mouth opening before treatment

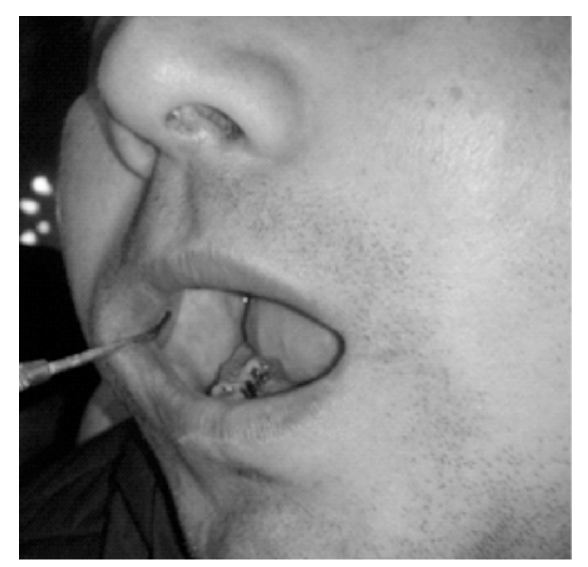

Figure 2: Palpable fibrous band in buccal mucosa

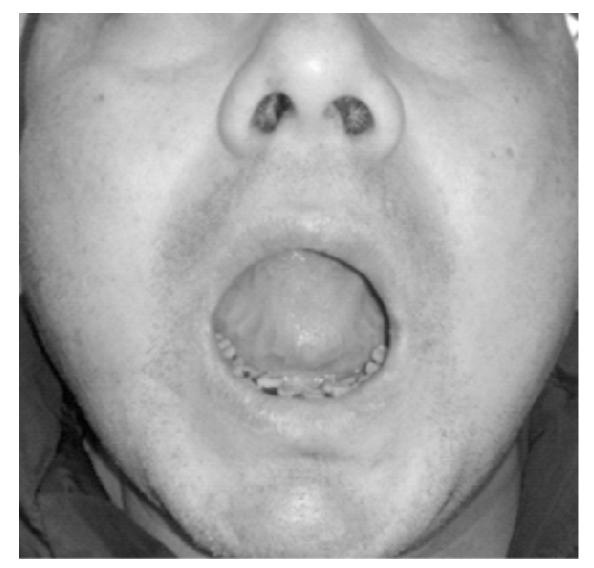

Figure 3: Mouth opening after treatment of 12 weeks
$(4 \mathrm{mg} / \mathrm{ml})$ plus Hyaluronidase $1500 \mathrm{IU}$ in each buccal mucosa for a period of 12 weeks. During every clinical evaluation the mouth opening was measured and burning sensation associated with the lesions were graded on VAS.

Patients were asked to report any adverse reactions or constitutional symptoms immediately. Again at monthly follow up visits, mouth opening and VAS scale were recorded.

\section{Statistical Analysis :}

The data was then statistically analyzed by using SPSS version 16.0. Descriptive statistics, Student's paired t test and Student's unpaired t tests were applied for statistical analysis. The level of significance was set at $p$-value of $<0.05$.

\section{RESULTS}

There were 40 male patients in the present study with mean age of $29.50 \pm 5.27$. The mean age of the 20 patients in Dexamethasone + Hyaluronidase group was $29.60 \pm 6.78$ years where as mean age of the other 20 patients in Colchicine group was $29.40 \pm 3.31$. The youngest patient was of 19 years and oldest was of 48 years. The maximum numbers of patients were in the age range of $26-30$ years in both study group. [ Table-I, Figure-4].

The major presenting complaints among all patients in both the groups was reduced mouth opening and burning sensation in the mouth on eating spicy food. In habit analysis it was noted that all the patients in both study group were having the habit of chewing gutkha, areca nut, pan and slaked lime.

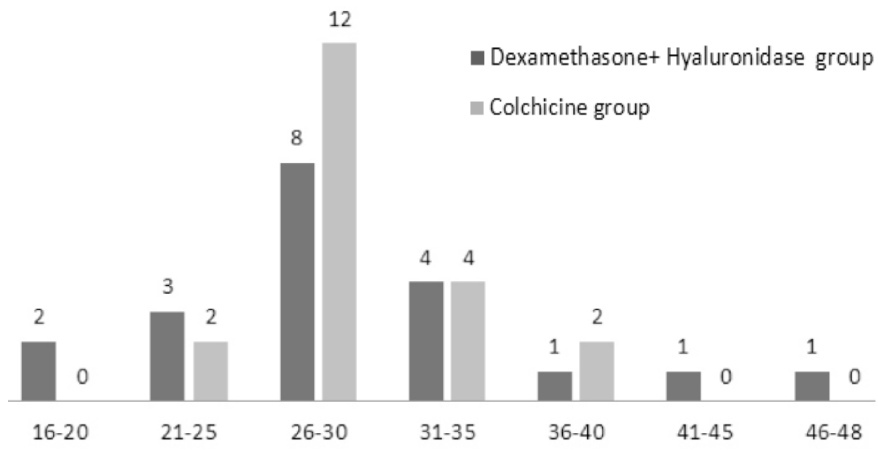

Figure 4: Distribution of Patients according to age group

\begin{tabular}{|c|c|c|c|c|c|}
\hline & \multicolumn{3}{|c|}{ Age Group } & Sex & Male \\
\hline Study Group & Mean Age & Minimum & Maximum & 20 & 20 \\
\hline $\begin{array}{c}\text { Dexamethasone }+ \\
\text { Hyaluronidase Group }\end{array}$ & $29.60 \pm 6.78$ & 19 & 48 & 20 & 20 \\
\hline Colchicine Group & $29.40 \pm 3.31$ & 25 & 37 & & 40 \\
\hline All Participants & $29.50 \pm 5.27$ & 19 & 48 & \\
\hline
\end{tabular}

Table I: Distribution of patients according to age in years 
Clinically, all the patients in both the groups were classified according to the classification proposed by Ranganathan $\mathrm{K}$ et. al. There were 9 patients in group II and 11 patients in group III in Dexamethasone + Hyaluronidase group . There were 8 patients in group II and 12 patients in group III in the dexamethasone + Hyaluronidase group. [Figure 5]

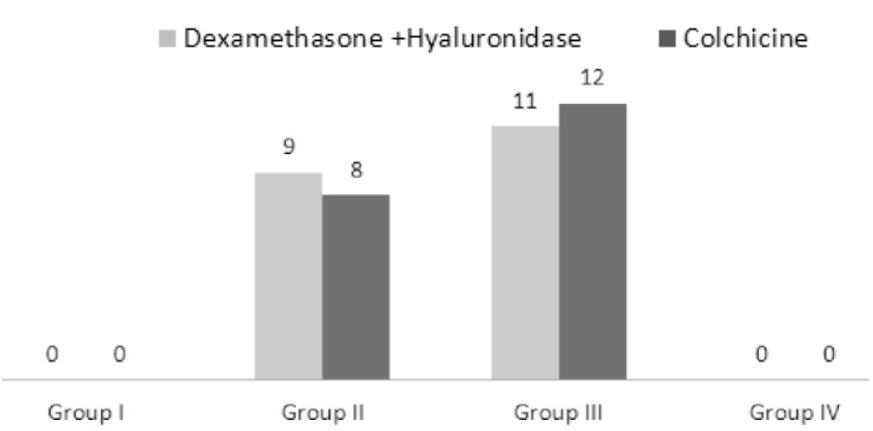

Figure 5:Distribution of OSMF patients in Dexamethasone + Hyaluronidase and colchicine
Mouth opening: In the present study, all the patients in both the groups showed improvement in moth opening. The median inter-incisal opening (MIIO) was recorded before the start of treatment and there on every month for a period of three 12 week. At baseline before treatment it was found that the average mouth opening in Dexamthasone+ Hyaluronidase group and Colchicine group was $19.65 \pm 4.00 \mathrm{~mm}$ and $18.90 \pm 3.24$ respectively. In Dexamethasone+ Hyaluronidase group and Colchicine group, the average increase in mouth opening from base line to $12^{\text {th }}$ week was $10.10 \pm 1.76 \mathrm{~mm}$ and $6.30 \pm 2.64 \mathrm{~mm}$ respectively. When the average mouth opening values at baseline and $12^{\text {th }}$ week of treatment were compared the differences were found to be statistically highly significant for both the groups. $(p<0.001)$ [Table II].

Burning sensation : In the present study, all the patients in both the groups showed reduction in burning sensation. At baseline, the average burning sensation as noted by VAS scale in Dexamethasone + Hyaluronidase and Colchicine group were $7.83 \pm 1.23$ and $7.16 \pm 1.16$ score respectively. The average decrease in burning sensation noted by VAS scale scores from

\begin{tabular}{|c|c|c|c|c|}
\hline \multicolumn{5}{|l|}{ Mouth opening $\mathrm{mm}$} \\
\hline Study Group & $\begin{array}{l}\text { Pre-treatment } \\
\text { (Mean } \pm S D)\end{array}$ & $\begin{array}{l}\text { Post treatment } \\
\text { (Mean } \pm \text { SD) }\end{array}$ & $\begin{array}{l}\text { Difference } \\
\text { (Mean } \pm S D \text { ) }\end{array}$ & p-value \\
\hline $\begin{array}{l}\text { Dexamethasone+ } \\
\text { Hyaluronidase }\end{array}$ & $19.65 \pm 4.00$ & $29.75 \pm 2.86$ & $10.10 \pm 1.76$ & $<0.001$ \\
\hline Colchicine & $18.90 \pm 3.24$ & $25.20 \pm 2.91$ & $6.30 \pm 2.64$ & $<0.001$ \\
\hline
\end{tabular}

Table II: Intra-group pre and post treatment analysis of improvement in mouth opening

\begin{tabular}{|c|c|c|c|c|}
\hline \multicolumn{5}{|c|}{ Burning Sensation (VAS) } \\
\hline Study Group & $\begin{array}{l}\text { Pre-treatment } \\
\text { (Mean } \pm S D)\end{array}$ & $\begin{array}{l}\text { Post treatment } \\
\text { (Mean } \pm \text { SD) }\end{array}$ & $\begin{array}{l}\text { Difference } \\
\text { (Mean } \pm S D \text { ) }\end{array}$ & p-value \\
\hline $\begin{array}{l}\text { Dexamethasone+ } \\
\text { Hyaluronidase }\end{array}$ & $7.83 \pm 1.23$ & $1.67 \pm 0.96$ & $6.16 \pm 1.12$ & $<0.001$ \\
\hline Colchicine & $7.16 \pm 1.16$ & $1.98 \pm 1.26$ & $5.18 \pm 1.38$ & $<0.001$ \\
\hline
\end{tabular}

Table III: Intra-group pre and post treatment analysis of improvement in burning sensation

\begin{tabular}{|c|c|c|c|}
\hline & $\begin{array}{c}\text { Dexamethasone+ } \\
\text { Hyaluronidase } \\
\text { (Mean } \pm \text { SD) }\end{array}$ & $\begin{array}{l}\text { Colchicine } \\
\text { (Mean } \pm \text { SD) }\end{array}$ & P value \\
\hline $\begin{array}{l}\text { Improvement in mouth } \\
\text { opening }\end{array}$ & $10.10 \pm 1.76$ & $6.30 \pm 2.64$ & $<0.001$ \\
\hline $\begin{array}{l}\text { Improvement in burning } \\
\text { sensation }\end{array}$ & $6.16 \pm 1.12$ & $5.18 \pm 1.38$ & 0.213 \\
\hline
\end{tabular}

Table IV: Intergroup Comparison of treatment outcomes (Unpaired t test) 
baseline to $12^{\text {th }}$ week was $6.16 \pm 1.12$ scores in Dexamethasone + Hyaluronidase group and $5.18 \pm 1.38$ score in Colchicine group. When the average VAS scores at baseline and at $12^{\text {th }}$ week of treatment were compared, the differences were found to be statistically highly significant for both the groups $(p<0.001)$ [Table III].

Intergroup Comparison: When the average differences of mouth opening from baseline to $12^{\text {th }}$ week of treatment was compared for Dexamethasone+ Hyaluronidase and Colchicine group it was significant stastistically $(p<0.001)$. But when the average differences of burning sensation was compared for Dexamrthasone+ Hyaluronidase and Colchicine no statistically significant difference was found for both treatment outcomes. [Table IV].

Adverse effects: Out of 20 patients in Dexamethasone + Hyaluronidase group all (100\%) complained of mild local pain following injection.

\section{DISCUSSION}

OSMF is a chronic debilitating condition with a high risk of malignant transformation. It is a chronic disease and differs in symptoms and severity at every stage ${ }^{19}$. Many surgical and therapeutic treatments have been tried for the cure of OSMF, but still no definitive or widely accepted treatment is currently available?

Intralesional injections of drugs like dexamethasone, triamcinolone, hyaluronidase and placental extract have shown relief from the symptoms and improvement in the mouth opening in patients with OSMF. Various combinations of drug regimens have been used in the treatment of OSMF and each drug has a different mechanism of action? ${ }^{7}$.

The mean age of patients having OSMF was $29.50 \pm 5.27$ years and all were male patients. This finding was similar to that of Mulk et al ${ }^{20}$ Aara et al ${ }^{21}$, Bhatta et al ${ }^{22}$. This is probably due to more outdoor activities in male and more accessibility of preparations ${ }^{22}$. Maximun patients were in age range of 26-30 years in both study group. In habit analysis all of the patients had habit of chewing gutkha, pan , areca nut. This finding was similar to that of Aara et al., ${ }^{21}$ Bhatta et $\mathrm{al}^{22} \mathrm{Shah}$ et $\mathrm{al}^{23}$. This finding emphasizes the role of areca nut as the main etiologic factor for OSMF ${ }^{23}$.

In the present study, increase in mouth opening and reduction in burning sensation were considered as two basic parameters to compare the efficacy of both the regimen. Statistically significant improvement was observed both in mouth opening and burning sensation with the use of hyaluronidase + dexamethasone combination indicating the efficacy of this regimen in the treatment of OSMF. Statistically significant improvement was also noted in mouth opening and burning sensation with the use of Colchicine as well, stating the usefulness of the Colchicine in the treatment of OSMF. [Table: II, Table III]
When the therapeutic effeicacy of both the regimen was compared, it was statsitiscally significant in mouth opening showing more increase in mouth opening with Dexamethasone + Hyaluronidase group than with Colchicine group. But the difference in reduction in burning sensation was not significant. These finding suggest that both drug regimen are effective in treatment of OSMF but superiority with Dexamethasone+ Hyauronidase. [Table IV]. Shah et al ${ }^{23}$ Aara et $\mathrm{al}^{21}$ evaluated the efficacy of hyaluronidase and dexamethasone combination in the treatment of OSMF and definite reduction in burning sensation and improvement in mouth opening was observed. These findings are similar to our study.

Krishnamoorthy et al $^{24}$ studied therapeutic efficacy of Colchicine in combination with intralesional hyaluronidase injections, and demonstrated favorable treatment outcomes in terms of mouth opening and burning sensation. The results was similar to our study. But in study of Krishnamoorthy et al., ${ }^{24}$ Colchicine was used in combination with hyaluronidase. In our study Colchicine was used alone.

Colchicine has been reported to be beneficial in the treatment of diseases associated with fibrosis in animals and human beings. ${ }^{25}$ The short and long term administration of Colchicine therapy in moderate dosages is surprisingly well tolerated. None of our patients reported any local or systemic adverse reactions during treatment with Colchicine and also after the cessation of drug intake. The most common toxic side effect of Colchicine mentioned in literature are nausea, vomiting, diarrhoea, and abdominal pain. These symptoms are especially frequent at dosage levels 2-3 mg/day although they are rapidly and completely reversible ${ }^{26}$.

In the present study all the patients in Dexamethasone + Hyaluronidase group reported post injection pain. This finding was similar to finding of Aara A et al., ${ }^{21}$ and Shah P et al., ${ }^{23}$.

\section{CONCLUSION}

In the present study, the improvement in mouth opening in oral submucous fibrosis patients showed better results by treatment with dexamethasone + Hyaluronidase than Oral Colchicine. Colchicine did show statistically significant improvement in mouth opening, decrease in burning sensation in oral submucous fibrosis patients. For this reason, it is concluded that Colcicine is a good alternative treatment for oral submucous fibrosis in patients in whom dexamethasone is contraindicated, or those who cannot make frequent visits for intralesional injections due to disability, far reaching places or any other reason. In such oral submucous fibrosis patients it is better to substitute Colchicine therapy rather than not to treat at all.

The encouraging results should prompt a clinical trial on more number of OSMF patients to broaden the therapeutic usefulness and applications of one of our most ancient treatment agents. This baseline study gives scope for further 
studies with the systemic use of Colchicine alone in the treatment of OSMF, and, also for research in the use of the drug as a formulation that can be administered locally into the fibrous bands to confirm the above result.

\section{LIMITATIONS}

The limitations of the present study include smaller sample size. The lack of awareness and motivation, the addiction potential of areca nut and the socioeconomic background of our patient population attributes to a high rate of loss to followup. These have led to the smaller sample size and influenced our study design.

\section{REFERENCES}

1. Jaitley S, Agarwal P, Upadhyay R. Role of oral exfoliative cytology in predicting premalignant potential of oral submucous fibrosis: $\mathrm{A}$ short study. Journal of cancer research and therapeutics. 2015; 11(2): 471-74.

2. Joshi J, More CB, Gupta S, Varma SN. Classification System for Oral Submucous Fibrosis. J Indian Aca Oral Med Radiol 2012; 24(1): 24-29.

3. Devesh T, Sunil D, Tripathi YC. Oral Submucous fibrosisi(OSMF): Premalignant threat to humanity with special reference to India. SMU Medical Journal.2015;2(1):281-290.

4. Anil S, Beena VT, Oral submucous fibrosis in 12-year old girl : case report. Journal of Paediatric dentistry.1993;16(2):120-22.

5. Murti PR, Bhonsle RB, Gupta PC, Daftary DK, Pindborg JJ. Mehta F $\mathrm{S}$. Etiology of oral submucous fibrosis with special reference to the role of arecanut chewing. J Oral Pathol. Med. 1995; 24 : 145152.

6. Ekanayaka RP, Tilakaratne WM. Oral Submucous Fibrosis: Review on mechanisms of pathogenesis and malignant transformation. J Carcinogene Mutagene.2013;1-11.(S5:002.doi:10.4172/21572518.S5-002).

7. Gupta J, Shrinivasan SV, Daniel JM. Effiacy of betamethasone, placental extract and hyaluronidase in the treatment of OSMF: a comparative study. E-Journal of Dentistry 2012;2(1):132-35

8. De Wall J, Oliver A, Van Wyk CW, Maritz JS. The fibroblast population in oral submucous fibrosis. J Oral Pathol Med. 1997; 26:69-74.

9. Aryawardana A, Athukorala ADS, Arulanandam A. effect of betal chewing, tobacco smoking and alcohol consumption on oral submucous fibrosi: A case- control study in Srilanka. J Oral Pathol Med. 2006; 35: 197-201.

10. Pindborg JJ, Bhonsle RB, Murti PR, Gupta PC, Daftary DK, Mehta FS. Incidence and early forms of oral submucous fibrosis. Oral Surg. 1980; 50 (1): 40-44.

11. Fareedi MA, Prasant MC, Ashok P, Vinit A, Safiya T, Rashmi D. Oral submucous fibrosis: medical management. GJMEDPH 2012;1(1): 12-19.

12. Naik SM, Appaji MK, Goutham MK. Comparative study of intralesional triamicinolone acetonide and hyaluronidase Vs placental extract in 60 cases of oral submucous fibrosis. Indian Journal of Head and Neck Surgery. 2012;3(2):59-65.

13. Venkatesh E. Role of corticosteroids in dentistry. Archives of Dental Sciences. 2010; 1(1):03-11.

14. Kakar PK, Puri RK, Venkatachalam VP. Oral submucous fibrosis treatment with Hylase. J Laryngol Otol. 1985;99(1):57-59.

15. Segovia A, Niembro RF, Ibanez KG, Alcocer G, Tamayo P. Long term evaluation of colchicine in the treatment of scleroderma. J Rheumatol. 1979;6:705-12.
16. Sapadin AN, Fleischmajer R. Treatment of Scleroderma. Arch Dermatol. 2002;138:99-105.

17. Diegelmann RF, Peterkofsky B. Inhibition of collagen secretion from bone and cultured fibroblasts by microtubular descriptive drugs. Proc Nat Acad Sci U S A. 1972;69:892-6.

18. Shwetha v, Brahamakumari YD. Efficacy and safety assessment of oxitard, a herbal antioxidant in oral submucous fibrosis- an observational clinical study. Indian Journal of Medical Research and Pharmaceutical Sciencs. 2016;3(7):48-53

19. Ali FM, Khare A, Bai $P$, Dungrani $H$, Purohit JN, Kumar S. A comparative study [9] of drug regimen of dexamethsone, hyaluronidase and placental extract with triamcinolone acetonide, hyaluronidase and placental extract in the intralesional injection treatment of oral submucous fibrosis. J Res Adv Den. 2015;4(1):1-6.

20. Mulk BS, Deshpande P, Velpula N, ChappidiV, Chintamaneni R, Goyal S. Spirulina and Pentoxyfilline - A Novel Approach for Treatment of Oral Submucous Fibrosis. Journal of Clinical and Diagnostic Research. 2013 Dec, Vol-7(12): 3048-3050.

21. Aara A, Vani C, Satishkumar GP, Reddy VM, Shreekanth K, Ibrahim M. Comparative study of intralesional dexamethasone, hyauluronidase, and oral pentoxifylline in patients with oral submucous fibrosis. Global Journal Of Medical Research.2012;12(7): 1-13.

22. Bhatta R, Pyakurel M. Clinical Profile of Oral submucous fibrosis. Nepalese Journal of ENT Head \& Neck Surgery. 2014; 5(1):5-7

23. Shah $\mathrm{PH}$, Venkatesh $\mathrm{R}$, More $\mathrm{CB}$, Vassandacoumara V. Comparison of Therapeutic Efficacy of Placental Extract with Dexamethasone and Hyaluronic Acid with Dexamethasone for Oral Submucous Fibrosis - A Retrospective Analysis. Journal of Clinical and Diagnostic Research. 2016 Oct;10(10): 63-66.

24. Krishnamoorthy B, Khan M. Management of oral submucous fibrosis by two different drug regimen: A comparative study. Dent Res J. 2013;10:527-32.

25. Guttadauria M, Diamond H, Kaplan D. Colchicine in the treatment of scleroderma. J Rheumatol. 1997;4:272-6.

26. Malkinson FD. Colchicine. Arch Dermatol. 1982;118:453-7.

27. Ranganathan K, Mishra G. An overview of classification schemes for oral submucous fibrosis. Journal of oral and maxillofacial pathology. 2006;10(2):55-8. 